\title{
Supervisão do enfermeiro no atendimento pré-hospitalar móvel
}

Nursing supervision in prehospital mobile assistance

Supervisión del enfermero en la atención prehospitalaria móvil

Andrea Bernardes ${ }^{1}$, Vanessa Gomes Maziero², Lívia Barrionuevo El Hetti ${ }^{3}$, Maria Cláudia dos Santos Baldin ${ }^{4}$, Carmen Silvia Gabriel ${ }^{5}$

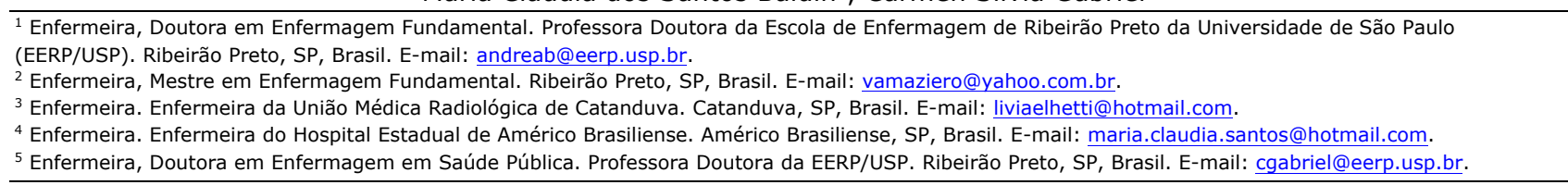

\section{RESUMO}

O estudo objetivou analisar como ocorre a supervisão no Serviço de Atendimento Móvel de Urgência (SAMU) de um município do Estado de São Paulo - Brasil. Estudo qualitativo que utilizou a análise temática de conteúdo para análise dos dados. A coleta de dados foi realizada em 2011, com o coordenador do SAMU e 27 auxiliares de enfermagem que trabalham nas viaturas de Suporte Básico de Vida. Emergiram duas categorias: Singularidades da Supervisão no APH móvel e Supervisão x Ruídos na comunicação. Os resultados revelaram que a supervisão foi considerada primordial nesse serviço, contudo é caracterizada como um processo de fiscalização. Além disso, os enfermeiros não estão presentes fisicamente nesse serviço, o que prejudica a qualificação dos profissionais. A comunicação enquanto instrumento da supervisão foi outra dificuldade elencada. Conclui-se que a supervisão não tem atendido às expectativas dos trabalhadores, favorecendo o risco de erros, comprometendo a segurança do paciente e da equipe.

Descritores: Supervisão de Enfermagem; Serviços Médicos de Emergência; Enfermagem; Comunicação.

\section{ABSTRACT}

The objective of this study was to analyze supervision of Mobile Emergency Assistance Service (SAMU, as per its acronym in Portuguese) in a municipality of the state of São Paulo, Brazil. A qualitative study using thematic content analysis for data analysis was developed. Data were collected in 2011 with a SAMU coordinator and 27 nursing aides who work in Basic Life Support vehicles. Two categories emerged: Singularities of prehospital assistance supervision and Supervision $\mathrm{x}$ Communication noise. The results indicate that supervision was considered primordial for this service. However, it is characterized more as an inspection process. Furthermore, nurses are not physically present in this service, a fact that hinders professional qualification. Participants also mentioned difficulties with communication as a supervision tool. In conclusion, supervision has not lived up to the workers' expectations, favoring the risk of errors, and compromising patient and staff safety.

Descriptors: Nursing, Supervisory; Emergency Medical Services; Nursing; Communication.

\section{RESUMEN}

Se objetivó analizar la supervisión en el Servicio de Atención Móvil de Urgencia (SAMU) de un municipio de São Paulo - Brasil. Estudio cualitativo, utilizando análisis temático de contenido para análisis. Datos recolectados en 2011, con el coordinador del SAMU y 27 auxiliares de enfermería actuantes en los vehículos de Soporte Básico de Vida. Emergieron dos categorías: Singularidades de la Supervisión en el APH móvil y Supervisión por Ruidos en la Comunicación. Los resultados revelaron que la supervisión fue considerada primordial en el servicio, sin embargo se la caracteriza como un proceso de fiscalización. Además, los enfermeros no están físicamente presentes en tal servicio, lo que perjudica la calificación de los profesionales. La comunicación como instrumento de supervisión fue otra dificultad mencionada. Se concluye en que la supervisión no ha atendido las expectativas de los trabajadores, favoreciendo el riesgo de errores, comprometiendo la seguridad del paciente y del equipo.

Descriptores: Supervisión de Enfermería; Servicios Médicos de Urgencia; Enfermería; Comunicación. 


\section{INTRODUÇÃO}

As iniciativas de construção da política federal para atenção às urgências no Brasil datam de 1998-2002, assinalado pela emissão de normas para implantação dos sistemas estaduais no atendimento de urgência, com a publicação da Portaria GM/MS no 2048, de 5 de novembro de 2002, que normatiza o Serviço de Atendimento Pré-Hospitalar Móvel. A partir de 2003, houve a formulação da Política Nacional de Atenção às Urgências e da estratégia do Serviço de Atendimento Móvel de Urgência ${ }^{(1)}$.

O SAMU foi criado em 1996 no município, cenário do estudo, com objetivo de estabilizar as condições vitais, reduzir o risco de morbimortalidade e realizar o transporte ao hospital de referência. Há no serviço a disponibilidade de Unidades de Suporte Básico de Vida (USB) que atendem pacientes com risco de morte desconhecidos, por meio de medidas conservadoras não invasivas; e a Unidade de Suporte Avançado de Vida (USA) que oferece apoio a pacientes em risco de morte, por intervenção de profissionais médicos através de medidas invasivas ou não-invasivas ${ }^{(2)}$.

Diante da proposta do Atendimento Pré-Hospitalar móvel (APHM), o enfermeiro é o profissional capacitado, que trabalha na supervisão da equipe de enfermagem, execução das prescrições médicas, assistência a pacientes grave, tomada de decisões e no controle da qualidade do serviço(3) ${ }^{(3)}$ Com o objetivo de conduzir o processo de trabalho gerencial na enfermagem, o enfermeiro deve atender as dimensões: cuidado, gerência, educação e pesquisa. Assim, o enfermeiro tem condição de desempenhar o papel articulador no sistema, na integralidade e integração ensino e cuidado, possibilitando a operacionalização dos serviços de saúde ${ }^{(4)}$.

Esse profissional vem assumindo de forma crescente a gerência de equipes e processos, envolvendo a coordenação e articulação das atividades realizadas por diversos profissionais ${ }^{(5)}$. Pensando-se nas práticas gerenciais, os enfermeiros não alcançam à práxis transformadora, pois adequam o trabalho aos coexistentes modelos gerenciais e assistenciais, ao depararem-se com a resistência das organizações dos serviços de saúde ao modelo neoliberal hegemônico ${ }^{(4)}$.

A edificação de novas formas de gerenciar que possibilitem o conhecimento e operacionalização das políticas de saúde, o incremento de competências e habilidades de liderança e gestão podem superar o modelo coexistente ${ }^{(6)}$.

Uma das importantes ferramentas de gestão é a supervisão que, no $\mathrm{APH}$, assume peculiaridades que a diferencia das demais instituições de saúde, visto que ainda hoje é feita à distância pelo enfermeiro.

De qualquer modo, é uma ferramenta essencial que possibilita garantir o sucesso dos atendimentos, especialmente pelo grau de complexidade das ações que requer habilidade, assistência imediata e livre de $\operatorname{riscos}^{(7)}$.

Para tanto, a supervisão deve fazer parte do programa de formação e capacitação do enfermeiro, sendo imprescindível o aprendizado sobre si mesmo, bem como da equipe de trabalho, conhecendo pontos fortes e fracos que influenciam o desenvolvimento profissional ${ }^{(8)}$.

Com relação à supervisão do enfermeiro, existem particularidades na rotina de trabalho do SAMU, pois, embora auxiliares e técnicos de enfermagem estejam subordinados ao enfermeiro, os mesmos prestam a assistência sob direção do médico regulador. Desse modo, é a causa frequente de tensão entre as equipes ${ }^{(9)}$.

Este estudo justifica-se pela incipiência de pesquisas científicas que abordem a supervisão, especificamente no Serviço de Atendimento Pré-Hospitalar Móvel. Além disso, analisar criticamente essa ferramenta na prática diária dos profissionais desse serviço oferece a oportunidade de aprimorar sua utilização, uma vez que possibilita distinguir limites, possibilidades, dificuldades e consequente qualificação no atendimento prestado.

Há a importância de se garantir que a supervisão ocorra de maneira eficiente nesse serviço móvel de urgência e emergência, uma vez que requer competência dos profissionais, objetivando condutas rápidas, eficientes e que atenda de maneira adequada, pertinentes a cada caso. Dessa forma, emergiu o seguinte questionamento: como se caracteriza a supervisão entre os profissionais que integram as viaturas de Suporte Básico de Vida e a coordenação do SAMU?

O objetivo do estudo foi analisar como ocorre a supervisão no Serviço de Atendimento Móvel de Urgência (SAMU) de um município do interior do Estado de São Paulo - Brasil, na visão do coordenador e de auxiliares de enfermagem.

\section{METODOLOGIA}

Trata-se de uma pesquisa descritiva dos fatos e fenômenos de determinada realidade. O estudo apresenta abordagem qualitativa que tem como objetivo conhecer as abrangências sociais, recomendado quando se tem pouco conhecimento sobre um fenômeno ou se 
pretende descrevê-lo de acordo com o ponto de vista do sujeito $^{(10)}$.

A investigação foi realizada em um Serviço de Atendimento Móvel de Urgência (SAMU) de um município situado na região nordeste do estado de São Paulo.

O serviço apresentado no estudo possui 11 viaturas de Suporte Básico de Vida (SBV) que ficam distribuídas nas diferentes Unidades Básicas Distritais de Saúde (UBDS) e duas viaturas de Suporte Avançado de Vida (SAV) que têm sua base própria. Os atendimentos são realizados por meio dos pedidos feitos pelo número 192, e os mesmos são distribuídos a partir da Central Única de Regulação Médica (CURM).

A Secretaria Municipal de Saúde coordena e administra o Programa de Assistência Médica Emergencial que é vinculado ao Departamento de Atenção à Saúde das Pessoas (DASP).

A coleta de dados foi realizada em 2011, com o coordenador do SAMU e 27 auxiliares de enfermagem que trabalham nas viaturas de Suporte Básico de Vida, somando 28 trabalhadores.

Do total de auxiliares de enfermagem que atuam nesse SAMU (70), quatro não aceitaram participar do estudo, 36 não estavam presentes no período da coleta de dados por motivo de folga, férias ou licença, e três tinham menos de um ano no serviço.

Os critérios de inclusão foram: estarem presentes e disponíveis no período da coleta de dados; terem disponibilidade de tempo para responder à entrevista; estarem trabalhando na instituição por, no mínimo, um ano.

Foi realizada entrevista áudio-gravada, não estruturada, na qual o entrevistado tem a possibilidade de discorrer sobre o tema proposto, sem resposta ou condições pré-fixadas pelo pesquisador ${ }^{(10)}$. Foi solicitado que os mesmos respondessem a questão norteadora: como se caracteriza a supervisão entre os profissionais que integram as viaturas de Suporte Básico de Vida e a coordenação do SAMU? A coleta de dados foi realizada pela própria pesquisadora no mês de junho de 2011, nos períodos diurno e noturno.

As entrevistas foram realizadas após autorização da Coordenação do Programa de Assistência Médica Emergencial para a realização das pesquisas, aprovação do Comitê de Ética em Pesquisa (Protocolo no 1266/2011) e da assinatura do Termo de Consentimento Livre e Esclarecido por todos os entrevistados, atendendo às exigências da Resolução 466/12 do Conselho Nacional de Saúde, sendo garantido o anonimato a todos os entrevistados.
As falas foram codificadas com a sigla " $A E$ " para Auxiliares de enfermagem e " $C$ " para Coordenador, seguida do número da entrevista ( $A E 1$ até $A E 27$ ) e (C).

Para análise dos dados optou-se pela utilização da análise temática de conteúdo descrita por Bardin ${ }^{(11)}$, que consiste em descobrir os núcleos de sentido que compõem uma comunicação cuja frequência signifiquem alguma coisa para o objetivo analítico visado, se organiza nas etapas: pré-análise; exploração do material e o tratamento dos resultados, inferência e interpretação.

A análise do material empírico permitiu o reconhecimento de núcleos de sentido que foram agrupados em três subcategorias: "o acesso aos enfermeiros supervisores e à coordenação", "aplicabilidade do processo educativo à realidade de trabalho" e "dificuldades na comunicação / supervisão de enfermagem". Tais subcategorias geraram duas categorias. A primeira diz respeito às peculiaridades do processo de supervisão do enfermeiro no APH móvel (Singularidades da Supervisão no APH móvel); a segunda trata das dificuldades do processo comunicativo, especialmente em decorrência da dificuldade no estabelecimento da supervisão nesse cenário (Supervisão x Ruídos na comunicação).

\section{RESULTADOS}

Dos 28 entrevistados, foram 24 mulheres $(88,9 \%)$ e quatro homens $(11,1 \%)$, com tempo de formação variando de cinco a 30 anos. Passa-se à análise das categorias elencadas.

\section{Singularidades da Supervisão no APH móvel}

Esta categoria contempla as peculiaridades da supervisão no APH móvel, especialmente no que se refere à distância em que ocorre.

Independentemente da maneira como acontece, a supervisão é uma das atribuições do profissional enfermeiro que trabalha no $\mathrm{APH}$ : "[...] dentre as competências e atribuições encontram-se: supervisionar e avaliar as ações da equipe no Atendimento PréHospitalar Móvel; executar prescrições médicas por telemedicina; prestar cuidados de enfermagem de maior complexidade técnica a pacientes graves e com risco de vida; ter capacidade de tomar decisões imediatas ${ }^{(12)}$."

Essa é também realidade de países desenvolvidos, como Canadá e Estados Unidos que recomendam que a supervisão ocorra desde a admissão, quando o trabalhador ainda está sendo capacitado para a atuação no ambiente pré-hospitalar ${ }^{(13)}$. 
Assim sendo, o enfermeiro deve compreender quão complexo e importante é seu papel de supervisor em uma equipe de Atendimento Pré-Hospitalar Móvel. Deve ainda entender que essa supervisão abrange, além da busca pela qualificação, o reconhecimento da sua importância.

Essa ferramenta é necessária para uma gerência de qualidade, de modo que, quando está ausente, pode levar as equipes a trabalharem de maneira desarticulada, pois o profissional acaba trabalhando da forma como acha conveniente e não da forma como é preconizada pela instituição, como pode ser observado na fala do entrevistado:

Eu acho que falta mais prática mesmo e mais fiscalização mesmo, por parte da chefia, pra equipe que estar trabalhando, isso é o que mais falta em minha opinião, porque campo tem, material pra trabalhar tem, treinamento tem, entendeu? Na hora tudo é muito lindo, na prática é que não tem ninguém que cuida, então o que falta é isso, um pouco mais de dedicação da parte assim da coordenação, da chefia, pra fiscalizar a prática[...](AE 7)

Conforme relatado, a supervisão é um dos instrumentos gerenciais utilizados pelo enfermeiro que advém do surgimento da administração como campo específico de saber e de prática na virada do século XIX para o início do século $\mathrm{XX}^{(14)}$. Essa ferramenta gerencial envolve a integração e coordenação dos recursos humanos e materiais ${ }^{(2)}$. Entretanto, os trabalhadores do SAMU em questão ainda entendem a supervisão como um processo de fiscalização e controle do processo de trabalho e não como um momento de orientação e educação, importante para o desenvolvimento e qualificação da equipe.

Essa realidade difere da adotada nos países de primeiro mundo, visto que há uma tendência de se contratar supervisores clínicos e educacionais nesses cenários $^{(13)}$.

Faz-se importante a adoção de estratégias similares no Brasil, visto que a supervisão deve ser vista como um processo educativo que vem sendo desenvolvido ao longo dos anos, transformando o conceito de supervisão fiscalizadora e punitiva para uma concepção mais próxima da Educação Permanente em Saúde. Esse é o momento em que são realizadas avaliações periódicas do trabalho da equipe de enfermagem, com o intuito de identificar necessidades para prevenir situações problemáticas, tendo como foco a melhoria da assistência prestada ao paciente na sua integralidade ${ }^{(15)}$.

Desse modo, não basta ao enfermeiro dominar a competência técnica para a supervisão, é imprescindível o entendimento das pessoas e dos grupos, da importância das relações de trabalho na internalidade da equipe para que a supervisão seja um instrumento qualificador da prática de enfermagem ${ }^{(14)}$. Tal ferramenta gerencial é a força motora de integração e de coordenação dos recursos humanos, envolvendo, sobretudo, o processo educativo, para que dessa forma se realize um trabalho eficiente e que atenda os requisitos da instituição e do paciente em todos os seus níveis de atenção.

Já a supervisão clínica permite a discussão do atendimento aos pacientes em um ambiente seguro e de apoio. Por meio dela, os enfermeiros são capazes de fornecer feedback e dar sugestões à equipe em um esforço para aumentar a compreensão sobre questões clínicas, sendo projetada para ser uma função educativa e não punitiva ou de fiscalização(16).

Paradoxalmente, é demonstrado pelos relatos dos auxiliares de enfermagem que os enfermeiros não se mostram presentes fisicamente nas USB, ainda que intermitentemente, o que contribui para o aumento dos riscos inerentes aos atendimentos prestados.

Precisaria ter um profissional mais perto. Junto conosco. Nós estamos pedindo isto já faz um tempo... Não tem uma enfermeira que ande nas ambulâncias com a gente. Então, às vezes é a enfermeira da USA que dá alguma orientação [...]. Então poderia melhorar se uma enfermeira estivesse de plantão junto com a gente, correndo com a gente, uma vez por semana "olha hoje vou ficar na viatura tal" pra ver as nossas técnicas, se nós utilizamos certo, para orientar alguma coisa, para melhorar, para crescer melhor nosso serviço. (AE 5)

Nota-se que a supervisão é considerada pelos auxiliares de enfermagem como uma atividade importante e requisito primordial para esse serviço de atendimento móvel. Concorda-se que "a supervisão é um aspecto administrativo utilizado como força motivadora de integração e coordenação dos recursos humanos e materiais que contribui para tornar possível a realização de um programa de trabalho de forma eficiente, com vistas a alcançar os objetivos da organização(2)."

Além disso, os profissionais deixaram claro que sentem falta da supervisão do profissional enfermeiro para orientá-los no decorrer da prestação do cuidado. É essencial que haja a promoção de programas educativos periódicos nesse serviço, bem como que haja a presença 
intermitente do enfermeiro como forma de possibilitar qualidade ao cuidado prestado(2).

Os auxiliares de enfermagem destacaram a importância da criação de protocolos que os norteiem e que padronizem a prestação da assistência em determinadas situações. No entanto, explicam que muitas vezes, em situação de urgência e emergência, o que é padronizado cede lugar ao improviso. Nessas situações, eles referem que sentem falta de uma supervisão de enfermagem para orientá-los sobre como agir e, se deparam, não só com a ausência dessa supervisão, mas com a dificuldade de acesso à coordenação e responsáveis técnicos (RT).

A gente segue o protocolo que a coordenação adequou pra gente de acordo com a situação. A gente tem o protocolo que nas situações de urgência a gente deve seguir, mas tem algumas coisas que fogem a algumas regras. Então é quando você sente falta. Aí, eles (operadores de rádio) tentam entrar em contato e caso não consigam, a gente tenta seguir o protocolo, mas não é a maneira mais segura porque tem coisas que fogem à regra e aí que está a nossa dificuldade. ( $A E 7)$

...Nada como você falar direto com a coordenação (de enfermagem), não passar nem pelo médico. Tem o protocolo, mas sempre tem aquelas, como se diz, sempre tem alguma coisa que foge ao protocolo e é nesse momento que a gente precisa e não tem a enfermeira $[\ldots](A E 7)$

Os auxiliares de enfermagem sentem-se inseguros na tomada de decisão e no desenvolvimento de alguns procedimentos, especialmente em situações mais complexas e, portanto, ratificam a importância da presença do enfermeiro supervisor no serviço.

Percebe-se o quão importante se mostra o papel de supervisor do enfermeiro para com os auxiliares de enfermagem que compõem as USB. Cabe salientar que para garantir efetividade na execução do trabalho de enfermagem, a supervisão, como dito, deve abranger principalmente o papel educativo, onde ambas as partes possam se comunicar, se expressar, e contribuir para o aprimoramento da execução do serviço e das relações interpessoais do grupo.

Estudo revela a experiência sueca sobre a supervisão do enfermeiro, assegurando que, nessa realidade, é essencial que haja um enfermeiro em cada viatura para garantir, especialmente, a administração de medicamentos $^{(17)}$.

Apesar das diferentes realidades encontradas mundialmente, nos cenários brasileiros é evidente a deficiência da supervisão de enfermagem no serviço préhospitalar, fato que contribui para o descontentamento de grande parte dos trabalhadores. Como solução para este problema, a maioria aponta para a presença ocasional do profissional enfermeiro nas viaturas, a fim de conhecer a realidade em que trabalham e formular intervenções para o que for conveniente para a melhoria do serviço.

Essa situação tende a ser resolvida, visto que o Conselho Federal de Enfermagem, por meio da Resolução no 375 de 2011, estabelece em seu artigo $1^{\circ}$ que a assistência de Enfermagem em qualquer tipo de unidade móvel destinada ao atendimento pré-hospitalar e interhospitalar, em situações de risco conhecido ou desconhecido, somente deve ser desenvolvida na presença do enfermeiro. O parágrafo $1^{0}$ desse artigo complementa que a assistência de enfermagem prestada por técnicos e auxiliares de enfermagem, somente poderá ser realizada sob a supervisão direta do Enfermeiro(18).

Contudo, essa ainda é uma realidade não alcançada, visto tal Resolução trazer itens conflitantes com a Portaria GM/MS n.o 2048 de 2002, que regula o sistema de urgência e emergência no país, que determina, dentre outras coisas, que as unidades de suporte básico de vida atuem com o técnico ou auxiliar de enfermagem e o condutor de veículo de emergência, ou seja, sem necessidade da presença constante do enfermeiro.

\section{Supervisão x Ruídos na comunicação}

Essa categoria reúne fala dos entrevistados sobre a dificuldade de comunicação entre os profissionais do serviço, fato que tem estreita relação com a ausência do enfermeiro supervisor.

Então é, primeiro passo seria ouvir nossas reivindicações, as nossas dificuldades, mas isso não acontece [...]. (AE 3)

Você nunca é ouvida pra chegar numa coisa melhor, eles fazem o que eles acham que seria bom. (AE 15)

Às vezes passamos por algumas situações, temos dúvidas ou tem que ter algum tipo de respaldo aí, não temos muito não, está tendo falha aí. Às vezes, um erro de comunicação, teve até uma ou duas reuniões, mas aí chega na reunião o povo começa a dispersar, um tema daqui uma outra coisa dali sabe, e acabamos não tendo resposta daquilo que a gente está tentando buscar. (AE 20)

A dificuldade na comunicação entre a equipe, o coordenador e responsável técnico do serviço foi algo que 
teve destaque nas entrevistas. Apesar de existirem reuniões periódicas, o estabelecimento de um processo comunicativo eficaz não se estabelece.

Contudo, a proposição de grupos de discussão caracteriza-se em importante ferramenta na geração de conhecimento, uma vez que o gestor, por meio dessas discussões, consegue passar aos funcionários o conhecimento solicitado pelos mesmos, além de oportunizar o estabelecimento do processo comunicativo efetivo.

Isto porque, para colocar decisões em prática e implantar as mudanças desejadas é necessário mais do que o acesso à informação. É fundamental gerar redes de conhecimento, visando a internalização das mudanças pretendidas. E, nada mais apropriado para a geração de mudanças, do que a formação de grupos de discussão acerca de uma determinada informação, onde o processo comunicativo em suas mais diferentes formas e tipologias se faz presente ${ }^{(19)}$.

A comunicação, principalmente para a área de urgência e emergência, deve ser uma estratégia contínua, sendo usada como ferramenta que contribua para segurança e clareza aos profissionais, justamente por ser uma área em que diariamente os profissionais lidam com situações estressantes que necessitam de grande atenção e entendimento das informações transmitidas $^{(20)}$. Assim, a comunicação dialógica é importante estratégia para o gerenciamento no SAMU, a fim de garantir eficiência e dinâmica nas atividades, proporcionando motivação e cooperação(21). Essa comunicação, nesse cenário, deveria ser intermediada pelo enfermeiro supervisor, uma vez que esse profissional, caso estivesse presente, seria o elo entre as viaturas e a Central de Regulação Médica, onde o coordenador e responsável técnico do serviço atuam.

Estudo realizado na Suécia também aponta para a importância de se estabelecer um processo comunicativo dialógico entre o supervisor e a equipe que trabalha no serviço pré-hospitalar. Os resultados mostram que a estratégia dialógica causou impacto na capacidade comunicativa dos participantes em geral e, eventualmente, influência positiva sobre as interações com pacientes e equipe ${ }^{(17)}$.

Para o gerenciamento de qualquer organização, o processo comunicativo é fator essencial para garantir que as atividades ocorram de maneira eficiente e eficaz, devendo acontecer constantemente a fim de proporcionar informação e compreensão necessárias à condução das tarefas e, acima de tudo, motivação, cooperação e satisfação nos $\operatorname{cargos}^{(22)}$.
A comunicação dos técnicos auxiliares de Regulação Médica (TARM) com as viaturas configura-se em outra dificuldade, na medida em que não detêm as informações detalhadas dos casos dos pacientes que serão atendidos. Essa situação reforça a necessidade da presença do supervisor como articulador entre os TARM e os trabalhadores que atuam nos veículos de urgência e emergência.

[...] a gente tem determinados chamados, a maioria deles a gente tem sim dificuldade [...] porque a gente conversa na central, as meninas não têm muita experiência e muita coisa que você fala pra ela, ela fala: Ok! Ela não tem noção do que você está falando, do que você está precisando no momento [...] Tem que começar a especialização desde lá da central, da forma de pegar o chamado, porque dificuldade a gente tem no dia-a-dia, às vezes passa um chamado pra nós: "olha, é uma dor de cabeça". Aí chega lá, já é uma parada. É um acidente leve, eles não tiram informação, a ambulância está indo [...] você chega lá e é grave [...] ( $\mathrm{AE} 18)$

Nota-se que as informações transmitidas aos trabalhadores das viaturas são escassas e por vezes errôneas, o que faz com que seja deslocada a viatura errada ao local de atendimento ou ainda que seja despendido um tempo maior no trajeto, tendo em vista o não reconhecimento da real gravidade do caso.

O coordenador e o responsável técnico pela equipe de enfermagem têm um papel essencial nesse processo, uma vez que devem aprimorar a qualidade do serviço por meio da supervisão com orientação constante das equipes, inclusive dos TARM. Tanto o coordenador quanto os RT, quando têm a capacidade de ouvir os trabalhadores, melhoram a relação interpessoal com a equipe de saúde, o que leva à satisfação no trabalho executado. Essa relação deve acontecer, sobretudo, de forma horizontal levando em conta o potencial de cada indivíduo, proporcionando vínculo, afeto e conhecimento por meio da identificação das necessidades de cada um.

Em estudo realizado com brasileiros especialistas em comunicação, a competência comunicativa, citada por mais de $50 \%$ dos participantes, foi "ouvir os outros". Assim, o outro se percebe ouvido e tem a oportunidade de expressar suas ideias, sendo a escuta ativa uma atitude compreensiva ${ }^{(23)}$.

$\mathrm{Na}$ avaliação da coordenação, o processo comunicativo é falho também por parte do profissional que atua nas viaturas, na medida em que eles não passam suas dificuldades diretamente à coordenação ou ao 
responsável técnico.

Não, também eles não passam nenhuma dificuldade disso, ele não vêm; porque um grupo menor você até consegue, um grupo maior você não consegue se organizar né. Então a gente põe alguns cursos de capacitação e eles fazem o curso. Até esse curso mesmo do Ministério houve uma chiadeira, que nem o curso eles queriam fazer, então veio através do pagamento de hora. A gente dá essas horas e vocês fazem o curso; agora trazer essas dificuldades eles falam, falam, mas não trazem as dificuldades, o serviço está aberto. (C)

Tal fato pode ser justificado pela dificuldade de articulação entre a coordenação e a equipe de trabalho. Muitas vezes, a direção dos serviços se coloca muito distante das equipes e da realidade do trabalho, e o profissional que está na ponta sente dificuldade em fazer essa aproximação. O enfermeiro supervisor poderia e deveria ser o articulador nesse caso.

Como a supervisão não se estabelece efetivamente, ficam mais evidenciados os problemas, dificuldades, saberes, pois a comunicação, além de apresentar um fluxo descendente, é extremamente formalizada, não permitindo a rapidez e a clareza necessárias à resolução dos problemas cotidianos ${ }^{(23)}$.

Estudo realizado com enfermeiros da atenção à saúde primária ratificou que a competência comunicativa é um campo do conhecimento que no trabalho diário possibilita relacionamento adequado entre os indivíduos $^{(24)}$. Essa competência comunicativa deve ser desenvolvida por profissionais da saúde e ser considerada como habilidade fundamental ao enfermeiro, ser expandida em cursos de graduação e especialização. Somente assim, o profissional poderá trabalhar com maior compromisso e apresentar maior resolutividade ${ }^{(22)}$.

Os modelos de gestão mais flexíveis têm como pressupostos a descentralização do poder e da autoridade, visando à elaboração de estratégias compartilhadas de resolução de problemas, com uma comunicação mais efetiva, tanto verticalmente, entre os diferentes níveis hierárquicos, como lateralmente, entre as unidades que compõem a organização(25). Neste contexto, novas estratégias devem ser pensadas, de modo que a comunicação se torne mais efetiva levando à articulação de todas as esferas, à resolução mais rápida de problemas cotidianos e à produção de serviços de qualidade ao usuário.

\section{CONSIDERAÇÕES FINAIS}

Com a elaboração do estudo foi possível perceber de que forma se dá a supervisão no atendimento préhospitalar móvel de um município do interior do Estado de São Paulo. Os auxiliares de enfermagem entrevistados entendem que a supervisão efetiva é importante instrumento para se garantir qualidade na prestação da assistência de enfermagem aos pacientes que se encontram em situações de urgência e emergência.

A supervisão foi considerada como uma ferramenta gerencial importante, primordial para o serviço de atendimento móvel. Contudo, os trabalhadores caracterizam essa ferramenta como um processo de fiscalização e pouco relacionada à educação permanente.

Além disso, os auxiliares de enfermagem mostramse descontentes com a supervisão, pois o fato dos enfermeiros não estarem presentes fisicamente nas USB contribui para o aumento dos riscos inerentes aos atendimentos prestados. Os mesmos sentem falta de momentos de orientação sobre como agir, uma vez que os atendimentos, nesse cenário, são imprevistos, demandando em várias situações, ações que não são estabelecidas em protocolos.

Como solução para essa problemática, os entrevistados sugerem a presença intermitente do enfermeiro supervisor nas viaturas. Assim, poderão avaliar o processo de trabalho, orientar e intervir nos atendimentos com vistas à melhoria do serviço.

Ao caracterizar a supervisão, a comunicação foi citada como importante instrumento gerencial. No entanto, algumas dificuldades foram detectadas no processo comunicativo entre auxiliares de enfermagem, coordenadores e responsáveis técnicos, fato que pode contribuir para elevar o risco de erros e agravamento de problemas no desenvolvimento do trabalho realizado pela equipe.

Dessa forma, foi possível analisar que a falta de comunicação eficaz, coloca em risco a qualidade da assistência prestada, além de gerar insatisfação aos trabalhadores envolvidos, acarretando em prejuízos à equipe.

Entretanto, foram sugeridas possibilidades para melhoria do serviço, como: a permanência de enfermeiros na Central de Regulação em tempo integral, a realização de reuniões regulares entre os trabalhadores e a coordenação, bem como a permanência da supervisão de enfermagem intermitente nas viaturas, com vistas à capacitação da equipe e consequente melhoria do atendimento prestado. 
Para ocorrer mudanças é necessário que o trabalho se organize de forma horizontal, afim de que o gestor e equipe trabalhem de forma harmônica e integrada. É papel do gestor proporcionar o bom relacionamento entre a equipe, precisamente escutar, orientar, mantendo, dessa forma, a harmonia e a qualidade da assistência prestada ao paciente que se encontra com agravos clínicos ou traumáticos, em situação de urgência ou emergência.

A limitação do estudo refere-se ao fato de que as entrevistas foram desenvolvidas apenas com auxiliares de enfermagem que trabalham nas viaturas de Suporte Básico de Vida de um Serviço de Atendimento Móvel de Urgência. Faz-se importante expandir a população de estudo, incluindo os enfermeiros das Unidades de Suporte Avançado de Vida, bem como os Responsáveis Técnicos destes e de outros serviços de Atendimento Pré-Hospitalar Móvel.

$$
\text { Contudo, a pesquisa trouxe contribuições }
$$

\section{REFERÊNCIAS}

1. Machado CV, Salvador FGF, O'Dwyer G. Mobile Emergency Care Service: analysis of Brazilian policy. Rev Gaucha Enferm [Internet]. 2011 [acesso em: 30 set 2014];45(3):519-528. Disponível em: http://dx.doi.org/10.1590/S003489102011005000022.

2. Bernardes A, Ramos BM, Betela Júnior J, Paiva PN. Supervisão do enfermeiro no atendimento pré-hospitalar móvel: visão dos auxiliares de enfermagem. Ciênc. cuid. saúde [Internet]. 2009 [acesso em: 30 set 2014];8(1):79-85. Disponível em:

http://dx.doi.org/10.4025/cienccuidsaude.v8i1.7778.

3. Martins CCF, Pontes AGV, Vieira AN, Santos VEP. Desgaste no serviço de atendimento pré-hospitalar móvel: percepção dos enfermeiros. Rev. enferm. UFSM [Internet]. 2012 [acesso em: 30 set 2014$] ; 2(2): 282-9$. Disponível em: http://cascavel.ufsm.br/revistas/ojs-

2.2.2/index.php/reufsm/article/view/4687.

4. Resck ZMR, Gomes ELR. Background and managerial practice of nurses: paths for transforming praxis. Rev Lat Am Enfermagem [Internet]. 2008 [acesso em: 30 set 2014];16(1):71-7. Disponível em:

http://dx.doi.org/10.1590/S0104-11692008000100012.

5. Erdmann AL, Backes DS, Minuzzi H. Care management in nursing under the complexity view. Online braz $\mathrm{j}$ nurs [Internet]. 2008 [acesso em: 30 set 2014];7(1). Disponível em: http://dx.doi.org/10.5935/1676-4285.20081033.

6. Guerra ST, Prochnow AG, Trevizan MA, Guido LA. Conflict in nursing management in the hospital context. Rev Lat Am Enfermagem [Internet]. 2011 [acesso em: 30 set 2014];19(2):362-9. Disponível em: http://dx.doi.org/10.1590/S0104-11692011000200019. 7. Bueno AA, Bernardes A. Percepção da equipe de enfermagem de um serviço de atendimento pré-hospitalar móvel sobre o gerenciamento de enfermagem. Texto Contexto Enferm [Internet]. 2010 [acesso em: 30 set 2014];19(1): 45-53. Disponível em: http://dx.doi.org/10.1590/S010407072010000100005.

8. Lindquist I, Johansson I, Severinsson E. Evaluation of processoriented supervision of student nurses: a Swedish case study. Nurs Health Sci [Internet]. 2012 [acesso em: 30 set 2014];14(1):2-7. Disponível em: importantes para a organização do trabalho gerencial dessa equipe que atua num cenário bastante complexo. Apesar da legislação atual favorecer a alocação de enfermeiros supervisores, ainda é incipiente a presença desse profissional nesse serviço. A supervisão à distância, muitas vezes realizada pelos responsáveis técnicos que permanecem apenas no horário comercial na Central de Regulação Médica, não tem atendido às expectativas dos trabalhadores das unidades de suporte básico de vida, favorecendo o aumento dos problemas e dos riscos de erros, comprometendo a segurança do paciente e da equipe. Dessa forma, este estudo evidencia aspectos a serem considerados no desempenho da supervisão realizada pelo profissional enfermeiro, bem como analisa o dissenso e reconhece as dificuldades do estabelecimento do processo comunicativo nessa realidade que impacta diretamente na qualidade dessa supervisão.

http://dx.doi.org/10.1111/j.1442-2018.2011.00628.x. 9. Alves M, Rocha TB, Ribeiro HCTC, Gomes GG, Brito MJM. Specificities of the nursing work in the mobile emergency care service of Belo Horizonte. Texto Contexto Enferm [Internet]. 2013 [acesso em: 30 set 2014];22(1): 208-15. Disponível em: http://dx.doi.org/10.1590/S0104-07072013000100025. 10. Minayo MCS. O desafio do conhecimento: pesquisa qualitativa em saúde. $11^{a}$ ed. São Paulo: Hucitec; 2010. 11. Bardin L. Análise de conteúdo. $4^{a}$ ed. São Paulo: Edições 70; 2010.

12. Ministério da Saúde. Regulação médica das urgências. Brasília: Ministério da Saúde; 2006. 126p.

13. McQueen $C$, Wyse $M$. The delivery of the new prehospital emergency medicine curriculum: reflections on a pilot programme in the UK. Emerg Med ] [Internet]. 2014 [acesso em: 30 set 2014$] ; 31(3): 233-7$. Disponível em: http://dx.doi.org/10.1136/emermed-2012-202141. 14. Carvalho JFS, Chaves LDP. Supervisão de enfermagem no contexto hospitalar: uma revisão integrativa. Rev. Eletr. Enf. [Internet]. 2011 [acesso em: 30 set 2014];13(3):546-53. Disponível em: http://dx.doi.org/10.5216/ree.v13i3.10381. 15. Liberali J, Dall'Agnol CM. Supervisão de enfermagem: um instrumento de gestão. Rev Gaucha Enferm [Internet]. 2008 [acesso em: 30 set 2014];29(2):276-82. Disponível em: http://seer.ufrgs.br/RevistaGauchadeEnfermagem/article/view/5 592.

16. Brunero S, Stein-Parbury J. The effectiveness of clinical supervision in nursing: an evidenced based literature review. Aust ] Adv Nurs [Internet]. 2008 [acesso em: 30 set 2014];25(3):86-94. Disponível em: http://www.ajan.com.au/Vol25/AJAN_25-3_Brunero.pdf. 17. Brink P, Bäck-Pettersson S, Sernert N. Group supervision as a means of developing professional competence within prehospital care. Int Emerg Nurs [Internet]. 2012 [acesso em: 30 set 2014];20(2):76-82. Disponível em: http://dx.doi.org/10.1016/j.ienj.2011.04.001.

18. Resolução COFEN No 375/2011, de 22 de março de 2011 (BR) [Internet]. Dispõe sobre a presença do Enfermeiro no Atendimento Pré-Hospitalar e Inter-Hospitalar, em situações de risco conhecido ou desconhecido. Brasília: Conselho Federal de Enfermagem; 2011 [acesso em: 30 set 2014]. Disponível em: http://www.cofen.gov.br/resoluo-cofen-n-3752011_6500.html. 
19. Carvalho H. A comunicação como fator crítico de sucesso nos processos de gestão da informação e do conhecimento nas organizações. UNIrevista. 2006;1(3):1-8

20. Santos MC, Bernardes A, Gabriel CS, Évora YDM, Rocha FLR. O processo comunicativo no serviço de atendimento móvel de urgência (SAMU-192). Rev Gaucha Enferm [Internet]. 2012 [acesso em: 30 set 2014];33(1):69-76. Disponível em: http://dx.doi.org/10.1590/S1983-14472012000100010. 21. Santos MC, Bernardes A. Comunicação da equipe de enfermagem e a relação com a gerência nas instituições de saúde. Rev Gaucha Enferm [Internet]. 2010 [acesso em: 30 set 2014];31(2):359-66. Disponível em:

http://dx.doi.org/10.1590/S1983-14472010000200022.

22. Braga EM, Silva MJP da. How Communication experts Express communicative competence. Interface (Botucatu) [Internet]. 2010 [acesso em: 30 set 2014];14(34):529-38. Disponível em: http://dx.doi.org/10.1590/S1414-32832010005000005.

23. Spagnol CA. Da gerência clássica à gerência contemporânea: compreendendo novos conceitos para subsidiar a prática administrativa da enfermagem. Rev Gaucha Enferm [Internet]. 2002 [acesso em: 30 set 2014];23(1):114-31. Disponível em: http://www.seer.ufrgs.br/RevistaGauchadeEnfermagem/article/vi ew/4405.

24. Witt RR, Almeida MC. Identification of nurses' competencies in primary health care through a Delphi study in southern Brazil. Public Health Nurs [Internet]. 2008 [acesso em: 30 set 2014];25(4):336-43. Disponível em:

http://dx.doi.org/10.1111/j.1525-1446.2008.00714.x. 25. Bernardes A, Cecílio LCO, Évora YDM, Gabriel CS, Carvalho MB. Modelo de gestão colegiada e descentralizada em hospital público: a ótica da equipe de enfermagem. Rev Lat Am Enfermagem [Internet]. 2011 [acesso em: 30 set 2014];19(4):1003-10. Disponível em: http://dx.doi.org/10.1590/S0104-11692011000400020.

Artigo recebido em 20/11/2012.

Aprovado para publicação em 05/02/2014.

Artigo publicado em 30/09/2014. 